\title{
Editorial: The Changing Face of Behavioural Psychotherapy
}

As this special issue took shape, it became increasingly clear that behavioural psychotherapy has come a long way. This means both the discipline and the Journal itself. The first issue of 1991 is an especially appropriate point to mark such advances, as the Journal of the British Association of Behavioural Psychotherapy is now published by Wisepress, who have a long-standing association with the BABP. In effect, this means that the journal is now published "in house", in the sense that Wisepress provide the BABP secretariat. We have chosen to reflect all of these changes in this special issue focussing on the development of behavioural psychotherapy as a discipline. The contributors to the special issue are all long-standing friends of the BABP and of this Journal.

In writing a recent conceptual and historical overview of cognitive behaviour therapy (in Hawton, Salkovskis, Kirk and Clark, 1989), it became apparent that Jack Rachman was not only there at the start of behavioural psychotherapy (and indeed the BABP), but that he has continued (and continues) to be involved at the leading edge of important professional and conceptual changes in behavioural psychotherapy. He opens the present issue with a glance into his crystal ball; he's seldom been wrong so far, so his analysis of present and future trends are of considerable interest.

One of the changes which Jack has influenced has been the recent shift towards the incorporation of cognitive factors. This emerges in several of the following papers, including the thoughtful review of classical conditioning by Marcel van den Hout and Harald Merkelbach and the useful analysis of the relationship between cognitive science and behaviour therapy by Mick Power. In my own contribution to this issue, I have considered the way in which the relationship between cognition and behaviour is conceptualized, and described a theoretical and practical solution to inconsistencies in current views of this important interaction. From a quite different perspective, Issac Marks highlights the changes which have taken place in our understanding and treatment of anxiety disorders, and provides important pointers for developments towards the more effective and efficient application of behavioural psychotherapy.

The special issue was planned well before the death of B. F. Skinner, perhaps the saddest indicator of the changing face of behavioural psychotherapy. It is therefore fitting that Chris Cullen's paper (and the obituary he kindly agreed to write for this issue) highlight the extent of Skinner's 


\section{P. M. Salkovskis}

contribution to the field. As his paper shows, this contribution and that made by others working from the tradition he developed underpins much of modern behavioural psychotherapy. Chris has dedicated his article to the memory of Skinner; I believe it only firting that the special issue also be similarly dedicated.

In the second section of this special issue, recent developments and possible future trends are considered in a range of key areas. The clear conclusion that can be drawn from this impressive range of work is that behavioural psychotherapy has developed to encompass an array of problems and approaches well beyond anything envisaged twenty years ago. It seems likely that future developments may well also exceed current expectations. In the April issue, the changes in behavioural psychotherapy will be considered within the context of the BABP as an evolving organization.

Despite the range of developments, it needs to be recalled that the BABP is not a professional organization, and that its future depends on the involvement and activities of the membership. As the BABP reaches its 20th anniversary and continues to increase in size, and as so many different fields are included, more involvement by the membership is needed. As editor of the BABP Journal, I hope that this will be reflected in articles sent to the journal, which is entirely dependent for material on its contributors; as a member of the BABP, I hope this will be reflected by the involvement of the membership in the association's activities.

Paul M. Salkovskis

\section{Reference}

The development and principles of cognitive-behavioural treatments. Chapter 1 in K. Hawton, P. M. Salkovskis, J. Kirk and D. M. Clark (Eds), Cognitive Behaviour Therapy for Psychiatric Problems: A Practical Guide. Oxford: Oxford University Press, 1989. 